\title{
Safety Assessment Requirements for Onsite Transfers of Radioactive Material
}

by

E. K. Opperman

Westinghouse Savannah River Company

Savannah River Site

Aiken, South Carolina 29808

E J. Jackson

A G. Eggers

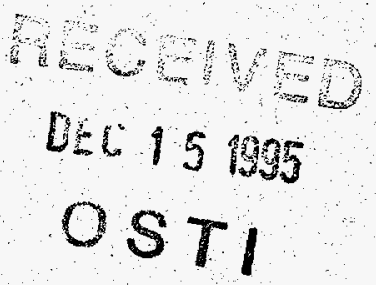

DOE Contract No. DE-AC09-89SR18035

This paper was prepared in connection with work done under the above contract number with the U.S.

Department of Energy. By acceptance of this paper, the publisher and/or recipient acknowledges the U.S.

Government's right to retain a nonexclusive, royalty-free license in and to any copyright covering this paper, along with the right to reproduce and to authorize others to reproduce all or part of the copyrighted paper. 


\section{Safety Assessment Requirements for Onsite Transfers of Radioactive Material (U)}

May 1992

Westinghouse Savannah River Company

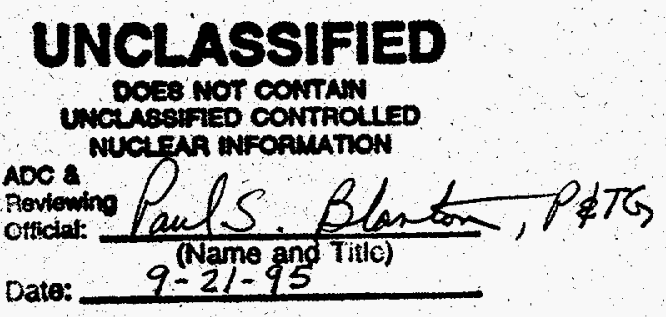
Savannah River Site Aiken, SC 29808 


\section{DISCLAIMER}

This report was prepared as an account of work sponsored by an agency of the United States Government. Neither the United States Govemment nor any agency thereof, nor any of their employees, makes any warranty, express or implied, or assumes any legal liability or responsibility for the accuracy. completeness, or usefulness of any information, apparatus, product, or process disclosed, or represents that its use would not infringe privately owned rights. Reference herein to any specific commercial product, process, or service by trade name. trademark. manufacturer, or otherwise does not necessarily constitute or imply its endorsement, recommendation, or favoring by the United States Government or any agency thereof. The views and opinions of authors expressed herein do not necessarily state or reflect those of the United States Governmeat or any agency thereof.

This report has been reproduced directly from the best available copy.

Available to DOE and DOE contractors from the Office of Scicatific and Technical Information, P. O. Box 62, Oak Ridge, TN 37831; prices available from (615) $576-8401$.

Available to the public from the National Technical Information Service, U. S. Deparment of Commerce, 5285 Port Royal Rd. Springfield, VA 22161 
WSRC-TR-92-580

\section{Safety Assessment Requirements for Onsite Transfers of Radioactive Material (U)}

\section{by}

R. J. Jackson

E. K. Opperman

A. G. Eggers

Packaging and Transportation Group Savannah River Technology Center 
WSRC-TR-92-580

This page is intentionally blank. 
$1.0 \quad$ INTRODUCTION $\ldots \ldots \ldots \ldots \ldots \ldots \ldots \ldots \ldots \ldots \ldots \ldots \ldots \ldots \ldots \ldots \ldots$

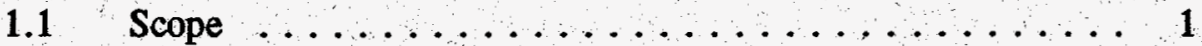

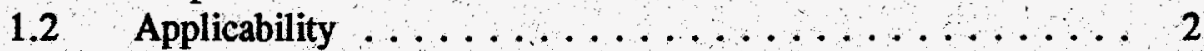

1.3 Approach $\ldots \ldots \ldots \ldots \ldots \ldots \ldots \ldots \ldots \ldots \ldots \ldots \ldots \ldots \ldots \ldots \ldots$

1.4 Review and Approval . ................. 2

1.5 Safety Assessment Introduction ............. 2

2.0 PACKAGE DESCRIPTION AND USE $\ldots \ldots \ldots \ldots \ldots \ldots \ldots$

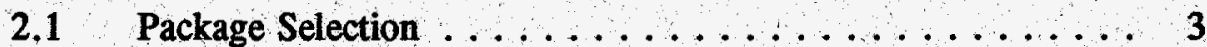

2.2 Package Description $\ldots \ldots \ldots \ldots \ldots \ldots \ldots \ldots \ldots \ldots$

2.3 Description of Authorized Material ...........6 6

2.4 Description of Authorized Usage . . . . . . . . . . 7

2.5 Description of Facility Interfaces . . . . . . . . . . 7

3.0 PACKAGE DESIGN REQUIREMENTS ........... 9

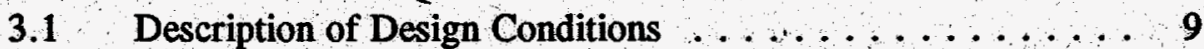

$3.2 \quad$ General Package Requirements $\ldots \ldots \ldots \ldots \ldots$

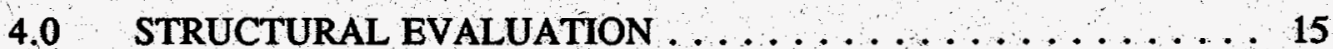

$4.1 \quad$ General Assessment $\ldots \ldots \ldots \ldots \ldots \ldots \ldots \ldots \ldots \ldots$

4.2 New Alternate Type B Packages $\ldots \ldots \ldots \ldots \ldots \ldots \ldots \ldots \ldots$

4.3 Existing Alternate Type B Packages . . . . . . . . . 16

4.3.1 Solid, Nondispersible Contents _.......... 16

4.3.2 Liquid or Dispersible Contents . . . . . . . . 16

$4.4 \quad$ All Other Alternate Packages $\ldots \ldots \ldots \ldots \ldots \ldots \ldots$

5.0 THERMAL EVALUATION $\ldots \ldots \ldots \ldots \ldots \ldots \ldots \ldots \ldots$

$5.1 \quad$ Alternate Type B Packages $\ldots \ldots \ldots \ldots \ldots \ldots \ldots \ldots \ldots$

5.2 Alternate Type A, IP-2, and IP-3 Packages $\ldots \ldots \ldots \ldots 18$

5.3 Excepted Packages ..................... 19

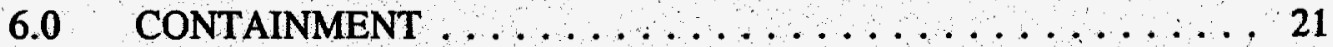

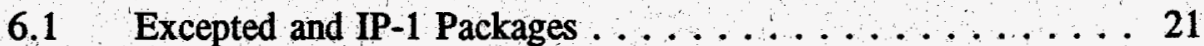

$6.2 \quad$ All Other Alternate Packages .............. 21

$7.0 \quad$ SHIELDING EVALUATION $\ldots \ldots \ldots \ldots \ldots \ldots \ldots \ldots$

7.1 Excepted and IP-1 Packages . . . . . . . . . . . 23

7.2 All Other Alternate Packages $\ldots \ldots \ldots \ldots \ldots \ldots \ldots \ldots$

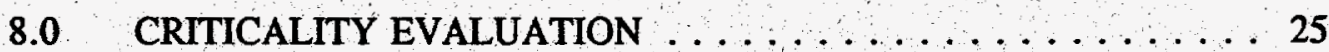

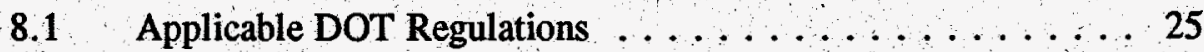

8.2 All Other Alternate Packages ............. 25

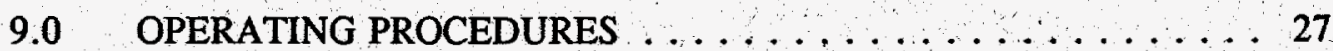

9.1 Excepted and IP-1 Packages . . . . . . . . . . 27

9.2 All Other Alternate Packages $\ldots \ldots \ldots \ldots \ldots \ldots$ 
CONTENTS (continued)

9.2.1. Operating Procedure Description ....... 27

9.2.2. Operating Procedure Assessment $\ldots \ldots \ldots \ldots 28$

10.0 ACCEPTANCE TESTING AND MAINTENANCE PROGRAM _ _ 29

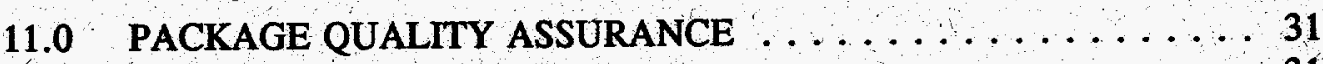

11.1 Alternate Type B Packages $\ldots \ldots \ldots \ldots \ldots \ldots \ldots$

11.2 All Other Alternate Packages ................. 31

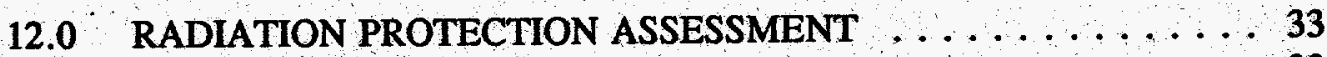

12.1 Excepted and IP-1 Packages . . . . . . . . . . . . 33

12.2 All Other Alternate Packages . . . .............. 33

13.0 HAZARDS INFORMATION ASSESSMENT $\ldots \ldots \ldots \ldots \ldots$

14.0 ASSESSMENT RESULTS AND REQUIREMENTS $\ldots \ldots \ldots \ldots$

14.1 Results .......................... 39

14.2 Requirements ................. 40

GLOSSARY $\ldots \ldots \ldots \ldots \ldots \ldots \ldots \ldots \ldots \ldots \ldots \ldots \ldots \ldots \ldots \ldots \ldots \ldots \ldots \ldots$ 


\section{LIST OF TABLES}

3.1 General Package Requirements for Alternate Onsite

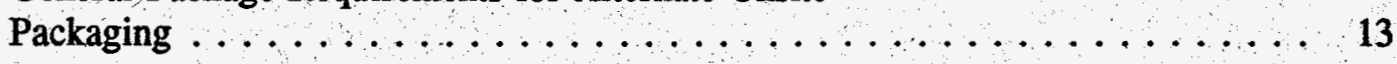


This page is intentionally blank. 


\subsection{INTRODUCTION}

\subsection{Scope}

This document contains the requirements for developing a safety assessment document for an onsite package containing radioactive material. This document also provides format and content guidance to establish uniformity in the safety assessment documentation and to ensure completeness of the information provided.

This document contains the following 14 chapters:

1. Introduction

2. General Information

3. Package Design Requirements

4. Structural Evaluation

5. Thermal Evaluation

6. Containment

7. Shielding Evaluation

8. Criticality Evaluation

9. Operating Procedures

10. Acceptance Testing and Maintenance Program

11. Quality Assurance

12. Radiation Protection Assessment

13. Hazards Information Assessment

14. Assessment Results and Requirements.

Introductory and background information and provided in Chapter 1. The requirements for review and approval of a safety assessment document are also contained in Chapter 1 .

In the body of this manual (Chapters 2 through 14) the format and content guidance for the safety assessment are provided. The results of the applicable analyses, tests, and comparisons of the package design, its contents, and its intended use with the applicable criteria are discussed in these chapters.

In the last chapter, the results of the safety assessment are compiled and the limits and requirements for package use are summarized. A description of the authorized contents and authorized usage for the onsite package is also contained in the last chapter.

A glossary follows the last chapter of this manual. 


\subsection{Applicability}

These requirements are applicable to all safety assessments for alternate packages (see Glossary) used for onsite transfer of radioactive material by Westinghouse Savannah River Company (WSRC). Whenever the requirements of the Environmental Protection Agency (EPA) for radioactive waste packages (i.e., package marking and labeling) conflict with these requirements, the requirements of the EPA have precedence.

\subsection{Approach}

The safety assessment document shall use the chapter titles and scope as described in this requirements document. Additional chapters and appendices may be used, if desired. This requirements document uses a format similar to that of the document specifying the acceptance criteria, Criteria for Onsite Transfers of Radioactive Material, WSRC-TR-92-579, which is referred to as the criteria document.

\subsection{Review and Approval}

The requirements for review and approval of each safety assessment document are contained in the associated criteria document (Chapter 2, Section 2.3). These requirements state that competent review of the safety assessment is required for each alternate package. The standards for these reviews are graded: the most stringent standards are used for the most hazardous package contents. The approval process results in a definition of the authorized package contents, authorized usage conditions, and any limits, restrictions, or requirements for the packaging, contents, or transfer-related activities. Those definitions of authorized contents, package usage, and operating requirements are included on the "Onsite Package Authorization" form.

\subsection{Safety Assessment Introduction}

The introductory chapter of the safety assessment document should provide an executive summary briefly describing the package, its usage, and conclusions regarding safe usage of the package for onsite transfer. The introductory chapter will identify any unique or special conditions established for use of the package for onsite transfers. 


\subsection{PACKAGE DESCRIPTION AND USE}

\subsection{Package Selection}

The package selection process is used to determine the preferred type of onsite transfer of radioactive material (unpackaged, authorized offsite packaging, or alternate onsite packaging). The package selection process is completed prior to the safety assessment. Package selection is based on ALARA considerations. The criteria for package selection are provided in the criteria document (Chapter 2, Section 2.2). The circumstances under which the use of alternate packaging is optional or mandatory are described in Section 2.2.3 of the criteria document. The rationale for selecting alternate packaging is summarized in this section.

\subsection{Package Description}

\section{Alternate Type B Packages}

The packaging description should include the following:

- gross package weight

- materials of construction

- materials used as neutron absorbers or moderators

- external dimensions and cavity size

- internal and external structures

- receptacles

- valves

- sampling ports

- means of heat dissipation

- volumes and types of coolant

- outer and inner protrusions

- lifting and tie-down devices

amount of shielding 
- pressure release systems

- closures.

Each containment and confinement boundary should be clearly identified. Overall and cutaway sketches ( $81 / 2$ by 11 in.) of the package are helpful, if included as part of the description.

Drawings that clearly detail the safety features considered in the analysis should be included in an appendix to the safety assessment. Detailed construction drawings of large, complex packages should not be included. The drawings should contain the following:

- materials list

- dimensions

- valves

- fasteners

- welder qualification requirements

- welding procedure qualification requirements.

Requirements for all packaging weld joints, specified by appropriate weld symbols, should be included. The method of nondestructive examination and the acceptance standard should be identified.

Gasketed joints in the containment system should be sufficiently detailed to show, as a minimum, the surface finish and flatness requirements of the closure surfaces, the gasket specification, and if appropriate, the method of gasket retention.

In the case of a complex package system, the operation of the package should be discussed. This discussion should include a schematic diagram showing the following:
- valves
- connections
- piping
- openings
- seals 
- containment boundaries

- other similar features.

Appendices to the safety assessment should include detailed descriptions of the following:

- operational features

- packaging contents.

The descriptive information can consist of dimensional drawings, detailed operational schematics, and loading configurations.

\section{All Other Alternate Packages}

The packaging description should include the following:

- authorized gross package weight

- materials of construction

- external dimensions

- cavity size

- any lifting and tie-down devices

- amount of shielding

- pressure relief systems

- closures

- each containment and confinement boundary clearly identified

- list of drawings necessary to fabricate the package.

The drawing list shall identify the revision number of each drawing describing the packaging discussed in the safety assessment document. Overall and cutaway, sketches ( $81 / 2$ by 11 in.) of the package are helpful, if included as part of the description. 


\subsection{Description of Authorized Material}

The description of the packaging authorized material contents should include the following:

- quantity of radionuclides

- chemical and physical form

- material density

- moderator ratios

- loading configurations

- decay heat.

This information is obtained from the "Material Characterization and Package usage Data Sheets," examples of which are provided in Appendix A of the criteria document. The completed data sheets should be included in an appendix to the safety assessment. The materials information from these data sheets should be compiled and summarized. The compilation shall be in a form that can serve as the basis for input to the structural, thermal, shielding, containment, and criticality analyses. In addition, the following material characteristics should be identified:

- any material incompatibility between the package contents and packaging components

- amount of hydrocarbons that might create gas from interactions with radiation

- all material characteristics with a potential for creating a subsidiary hazard.

The summary shall be in a form that can serve as the description of the authorized contents. The description of the authorized contents shall encompass the range of the material characteristics on all applicable data sheets.

If, desired, the material characteristics may be cited as a range of parameters that includes the specific characteristics of the contents currently being authorized for onsite transfer. This would, in principle, permit using the alternate packaging for other contents that fall within the range without the need to revise the safety assessment. A range of material characteristics should be included in the description of the authorized contents only if minimal additional costs are required to justify package authorization. For an existing alternate onsite packaging, the additional costs involve the safety assessment development, review, and approval. 
For a newly designed alternate packaging, the additional costs also include any additional design, analysis, testing, fabrication, and quality assurance efforts.

\subsection{Description of Authorized Usage}

The description of the package usage includes the following:

- package loading locations

- destinations

- routes used

- how the package is handled while loading and unloading

- type of transport vehicle used

- frequency of transfers

- other usage-related safety or design information.

This information is obtained from the "Material Characterization and Package Usage Data Sheets" provided in Appendix A of the criteria document. The package usage information from these data sheets shall be compiled and summarized. The compilation shall be in a form that can serve as the basis for deriving the list of credible events described in the criteria document (Chapter 3, Section 3.2.1).

The summary shall be in a form that can serve as a description of the authorized package use. If use of the package for storage of its contents for greater than 90 days is intended, that storage usage shall be included in the usage description. If the package is placed in storage in a loaded configuration (with its contents and sealed) and is not vented or reopened prior to the transfer, then the storage times and conditions shall be included in the package usage description. The storage times and conditions for any interim storage during the transfer shall also be included in the package usage.

\subsection{Description of Facility Interfaces}

The description of the facility interfaces includes the following:

- handling limitations

- hoisting requirements

- portal requirements (size restrictions) 
Safety Assessment Requirements for Onsite Transfers of Radioactive Material (v)

- space limitations for storage and movement from storage locations to loading and unloading locations within a facility

- any other unique requirements or limits at the shipping or destination points.

This information is obtained from the "Material Characterization and Package Usage Data Sheets" provided in Appendix A of the criteria document. The information complied in this section:

- ensures that all interface requirements on the data sheets are included

- permits a comparison of the interface requirements with the package description to assure the functionality of the package design. 
Safety Assessment Requirements for Onsite Transfers of Radioactive Material (U)

\subsection{PACKAGE DESIGN REQUIREMENTS}

The packaging design shall be assessed to determine if the packaging with its authorized contents meets all design requirements. These design requirements are included in the list of general package requirements provided in Section 3.1. These design requirements are established to ensure that the package provides adequate protection to workers, members of the public, and the environment during normal intended usage and other credible events that can be hypothesized to occur.

\subsection{Description of Design Conditions}

The information on design conditions expected to be experienced by the package during its intended usage is obtained from the "Material Characterization and Package Usage Data Sheets" provided in Appendix A of the criteria document." The information from these data sheets that shall be compiled and summarized in this section of the safety assessment is as follows:

- external loads during operation

- ambient conditions during storage with contents

- unique requirements or limits.

Pressure buildup could occur during storage of a package prior to onsite transfer or interim storage during the onsite transfer process. If there is a possibility of pressure buildup, the storage conditions and durations must be determined and described in this section.

Determination of the package internal pressure shall consider the maximum pressure buildup during storage of the package prior to onsite transfer. The maximum pressure expected during.storage should be reported in this chapter of the safety assessment.

A list of credible events in the Normal, Anticipated, Off-normal, and Emergency event categories must be developed. This list should be included in the safety assessment document. Examples of events in each category are listed in Table 3.1 of the criteria document. The information provided in the material characterization and package usage data sheets should be used to develop a package specific list of events unless a generic list is used.

\section{Normal and Anticipated Credible Events}

The criteria document permits the lists of normal and anticipated events to be based upon package usage and local site specific conditions. As another option, the 
Safety Assessment Requirements for Onsite Transfers of Radioactive Material (U)

criteria document permits the normal and anticipated events to be represented by the tests in 49 CFR 173.465 and 49 CFR 173.466.

If these event lists are based upon package usage and local conditions, the lists must be properly justified in the safety assessment. This may be done by using a recognized methodical process to assign probabilities to the events. The probabilities determine which event category the event falls into.

No further justification is required if the tests listed in 49 CFR 173.465 and 49 CFR 173.466 are used for credible events. Passing the tests or surviving the credible events may be shown by analysis, testing, comparison with existing packages, or a combination of these techniques.

\section{Off-normal and Emergency Credible Events}

The criteria document permits the lists of off-normal and emergency events to be based upon package usage and local specific conditions. As another option, the criteria document permits the off-normal and emergency events to be represented by tests and conditions listed in 10 CFR 71.73 .

No justification is required if the tests listed in 10 CFR 71.73 are used for the offnormal and emergency events. If these event lists are based upon package usage and local conditions, the lists must be properly justified in the safety assessment. This may be done by using a recognized methodical process to assign probabilities to the events. The event probabilities determine which event category the event falls into.

To minimize the labor involved with the development of credible events that are specific to onsite transfers by truck, a generic list of credible events for truck transfers was developed based upen probability of occurrence. These credible events are represented by tests, similar to the offsite test requirements for hypothetical accident conditions. A list of tests has been developed to represent the off-normal events (Table 3.2 of the criteria document). A separate list of tests has been developed to represent the emergency events (Table 3.3 of the criteria document). Because of the assumptions used in the development of these generic tests, the tests are applicable only to truck transfers of packages weighing at least 3.000 pounds and having no more than 1,000 loaded truck miles per year. If desired, these generic tests may be used without further justification to represent the transport phase of an onsite transfer. If the generic tests are used, it is necessary to also identify the package specific credible events associated with loading and unloading the package from the truck.

The generic tests must be considered in the order they are listed in Tables 3.1 and 3.2 of the criteria document. Passing the tests or surviving the credible events may be shown by analysis, testing, comparison with existing packages, or a combination of these techniques. 


\section{Design Basis Events}

Design basis events shall be selected from the list of credible events for each of the event categories. Each design basis event shall be the combination of worst-case credible events for that event category and the worst-case combination of radionuclides for that failure mode. For example, the design basis emergency event for containment is as follows:

- the credible emergency event causing the most damage affecting containment, combined with

- the mixture of those radionuclides (within the ranges permitted by the authorized contents) that cause the largest health effect if released into the air or water.

Similarly, the design basis emergency event for shielding is as follows:

- the credible emergency event causing the most damage affecting shielding, combined with

- the mixture of those radionuclides (within the ranges permitted by the authorized contents) that cause the largest health effect from penetrating radiation, i.e, gammas and neutrons.

All normal events collectively and the applicable design conditions are the design basis for normal conditions.

The following non-normal design basis events shall be identified:

- design basis anticipated events for containment, shielding, and criticality

- design basis off-normal events for containment, shielding, and criticality

- design basis emergency events for containment, shielding, and criticality.

The collective set of design conditions for normal events and non-normal design basis events are the required conditions under which the package must be shown to adequately perform. The set of design conditions and design basis events should be listed in the safety assessment document.

\subsection{General Package Requirements}

The general package requirements for alternate onsite packaging are listed in Table 3.1. New alternate onsite packages shall be designed, fabricated, and used such that they meet the requirements in the table. Existing alternate onsite 
packages shall be evaluated to ensure that their design and use meet the requirements in the table.

The technical assessment (i.e., analyses, tests, and/or comparisons) showing compliance with the 13 requirements exists in more than one chapter of the safety assessment. For example, to demonstrate that Requirement 2 regarding radiation shielding components of the package is met, a structural analysis (Chapter 4) to determine how these features may be affected by the design basis events established for the package. On the basis of the results of the structural analysis, a shielding analysis (Chapter 7 ) is performed to determine the radiation dose levels associated with the package for these design basis events. Finally, a radiation protection assessment (Chapter 12) is made to determine the exposure to onsite workers and members of the public. In addition, to demonstrate that the radiation shielding components function as designed throughout the useful life of the package, the applicable quality assurance requirements must be met. Also, the applicable operating procedures, acceptance tests, and maintenance procedures must be established. Thus, the chapters cited in the third column of Table 3.1 are examples of places within the safety assessment document in which compliance with these general requirements is discussed. 
Safety Assessment Requirements for Onsite Transfers of Radioactive Material (I)

Table 3.1. General Package Requirements for Alternate Onsite Packaging

\begin{tabular}{|c|c|c|}
\hline $\begin{array}{c}\text { Requirement } \\
\text { Number }\end{array}$ & Requirement & $\begin{array}{l}\text { Examples of Safety } \\
\text { Assessment Chapters in } \\
\text { which Fulfilment of } \\
\text { Requirement is Evaluated }\end{array}$ \\
\hline 1 & $\begin{array}{l}\text { The impact resistance, strength, confinement } \\
\text { and containment capability, thermal capacity, } \\
\text { and other features important to safety provide } \\
\text { required protection to workers, members of the } \\
\text { public, and the environment from radiation } \\
\text { exposure during normal operations and all other } \\
\text { design basis events for containment. }\end{array}$ & $\begin{array}{l}\text { Chapter } 4 \text {, structural } \\
\text { Chapter } 5 \text {, thermal } \\
\text { Chapter } 6 \text {, containment } \\
\text { Chapter } 12 \text {, radiation } \\
\text { protection }\end{array}$ \\
\hline 2 & $\begin{array}{l}\text { Radiation shielding components provide the } \\
\text { required protection to workers, members of the } \\
\text { public, and the environment from external } \\
\text { radiation exposure during normal operations } \\
\text { and all other design basis events for shielding. }\end{array}$ & $\begin{array}{l}\text { Chapter } 4 \text {, structural } \\
\text { Chapter } 7 \text {, shielding } \\
\text { Chapter } 12 \text {, radiation } \\
\text { protection }\end{array}$ \\
\hline 3 & $\begin{array}{l}\text { The packaging maintains the contents in } \\
\text { subcritical condition during normal operations } \\
\text { and all other design basis events for criticality. }\end{array}$ & $\begin{array}{l}\text { Chapter } 4, \text { structural } \\
\text { Chapter } 8 \text {, criticality }\end{array}$ \\
\hline 4 & $\begin{array}{l}\text { Excessive stress from melting of solid contents } \\
\text { or from expansion of liquid contents from } \\
\text { temperature increases is precluded. Excessive } \\
\text { overpressure from water vapor expansion from } \\
\text { temperature increases during normal operations } \\
\text { and all other design basis events is precluded. }\end{array}$ & $\begin{array}{l}\text { Chapter } 4 \text {, structural } \\
\text { Chapter } 5 \text {, thermal }\end{array}$ \\
\hline 5 & $\begin{array}{l}\text { Failure of any tie-down attachment from } \\
\text { excessive load will not impair the function of } \\
\text { any packaging safety system. }\end{array}$ & $\begin{array}{l}\text { Chapter } 4 \text {, structural } \\
\text { Chapter } 5 \text {, thermal }\end{array}$ \\
\hline 6 & $\begin{array}{l}\text { Incompatibility (including corrosivity, } \\
\text { permeability, softening, premature aging, } \\
\text { embrittlement, and chemical or galvanic } \\
\text { reaction) between the packaging components, } \\
\text { and between the components and the packaging } \\
\text { contents is precluded. }\end{array}$ & Chapter 4 , structural \\
\hline
\end{tabular}


Table 3.1. General Package Requirements for Alternate Onsite Packaging

(Continued)

\begin{tabular}{|c|c|c|}
\hline $\begin{array}{c}\text { Requirement } \\
\text { Number }\end{array}$ & Requirement & $\begin{array}{l}\text { Examples of Safety } \\
\text { Assessment Chapters in } \\
\text { which Fuifillment of } \\
\text { Requirement is Evaluated }\end{array}$ \\
\hline 7 & $\begin{array}{l}\text { Protection against all subsidiary hazards is } \\
\text { provided. }\end{array}$ & $\begin{array}{l}\text { Chapter } 4 \text {, structural } \\
\text { Chapter } 5 \text {, thermal }\end{array}$ \\
\hline 8 & $\begin{array}{l}\text { Any gas created inside a package, during use } \\
\text { or while the package is in storage prior to use, } \\
\text { does not cause an overpressure, fire, or } \\
\text { explosive hazard. }\end{array}$ & $\begin{array}{l}\text { Chapter } 4 \text {, structural } \\
\text { Chapter } 5 \text {, thermal }\end{array}$ \\
\hline 9 & $\begin{array}{l}\text { Penetrations through containment boundaries } \\
\text { are protected from damage during use. }\end{array}$ & Chapter 4 , structural \\
\hline 10 & $\begin{array}{l}\text { Containers involving any significant gas } \\
\text { buildup, automatic pressure relief, or other } \\
\text { venting cause no personnel radiation exposure } \\
\text { or spreading of contamination from any release } \\
\text { during normal operation and cause exposure or } \\
\text { spread of contamination that is less than } \\
\text { established limits during other design basis } \\
\text { events. }\end{array}$ & $\begin{array}{l}\text { Chapter } 6 \text {, containment } \\
\text { Chapter } 12 \text {, radiation } \\
\text { exposure assessment }\end{array}$ \\
\hline 11 & $\begin{array}{l}\text { Decontamination is facilitated to the extent } \\
\text { practical. }\end{array}$ & $\begin{array}{l}\text { Chapter } 9 \text {, operating } \\
\text { procedures } \\
\text { Chapter } 10 \text {, acceptance } \\
\text { testing and } \\
\text { maintenance program }\end{array}$ \\
\hline 12 & $\begin{array}{l}\text { Inner packagings of combination packagings } \\
\text { are packed and secured such that: } \\
\text { a) closures are upright } \\
\text { b) breakage or leakage is prevented } \\
\text { c) movement in the outer package is } \\
\text { controlled. }\end{array}$ & $\begin{array}{l}\text { Chapter } 9 \text {, operating } \\
\text { procedures }\end{array}$ \\
\hline 13 & $\begin{array}{l}\text { The authorized gross weight is legibly marked } \\
\text { on each alternate Type B packaging. }\end{array}$ & $\begin{array}{l}\text { Chapter } 9 \text {, operating } \\
\text { procedures }\end{array}$ \\
\hline
\end{tabular}


Safety Assessment Requirements for Onsite Transfers of Radioactive Material (U)

\subsection{STRUCTURAL EVALUATION}

Packaging structural integrity may be established by analysis, testing, or comparison or by a combination of analysis, testing, and comparison. For all loads identified in the description of the package design conditions (Section 3.1), the following items shall be considered and their effects discussed:

- containment

- shielding

- lifting and tie-down functions

- stress, strain, or deformation

- structural stability

- brittle fracture

- fatigue failure modes during operation
- gas buildup

- contents freezing or melting

- corrosion

- chemical or galvanic reaction

aging

embrittlement.

\subsection{General Assessment}

This section of the safety assessment document shall discuss how the packaging meets the general criteria in Chapter 4 , Section 4.1 , of the criteria document.

If the assessment is by comparison to existing authorized packagings, the important characteristics of the authorized packaging should be listed. For example, if the failure mode being considered is breach from internal pressure, the important characteristics of the authorized package are the thickness and the diameter of the pressure retaining wall (i.e., the $t / d$ radio) and the allowable internal pressure. Thus, for this example the comparisons would be between the $t / d$ ratios and allowable internal pressures of the two packagings with similar designs and materials of construction.

\subsection{New Alternate Type B Packages}

The results of structural analyses and tests of new Alternate Type B packages shall be presented in this section of the safety assessment document. Calculational approaches and assumptions used should be identified and discussed. Comparison of calculated values with the structural criteria in Chapter 4, Section 4.2 of the criteria document, should be listed. Results should be summarized and conclusions regarding compliance with the established criteria should be stated. 


\subsection{Existing Alternate Type B Packages}

The results of structural analyses of existing Alternate Type B packagings shall be presented in this section of the safety assessment document. Calculational approaches and assumptions used should be identified and discussed. Comparison of calculated values with structural criteria in Chapter 4 , Section 4.3 should be listed. Results should be summarized and conclusions regarding compliance with the established criteria should be stated.

\subsubsection{Solid, Nondispersible Contents}

If stresses in the closure components exceed the structural criteria, the safety assessment document shall discuss how the package meets the additional criteria for solid, nondispersible contents listed in Chapter 4 , Section 4.3 of the criteria document.

\subsubsection{Liquid or Dispersible Contents}

If stresses in the closure components exceed the structural criteria, the safety assessment document shall discuss how the package meets the additional criteria for liquid or dispersible contents listed in Chapter 4 , Section 4.3 of the criteria document.

\subsection{All Other Alternate Packages}

The results of structural analyses of all other onsite alternate packagings shall be presented in this section of the safety assessment document. Calculational approaches and assumptions used should be identified and discussed. Calculated values should be compared with the applicable structural criteria in the criteria document. Results should be summarized and conclusions regarding compliance with the established criteria should be stated.

For all other alternate packages, only the normal and anticipated design basis events are considered in the safety assessment document. 


\subsection{THERMAL EVALUATION}

\subsection{Alternate Type B Packages}

For alternate Type B packagings, the thermal evaluation chapter of the safety assessment document shall:

- Identify, describe, discuss, analyze, and/or test the principal thermal engineering design of the packaging components and systems important to safety and to compliance with performance requirements established for onsite transfers.

- Describe the significant thermal design features and operating characteristics of the packaging.

- Discuss the operation of all sub-systems involved in thermal control.

This section shall also identify or describe the following additional items:

- Any thermal criteria applicable to the thermal results (change of state temperature for package components or contents, or effective temperature limits for package components).

- Any properties evaluated here but used in other analyses (pressure, temperatures, and temperature distributions creating thermal stresses).

- Maximum decay heat loads (and minimum, if low temperature might cause freezing of contents or malfunction of packaging components).

- Thermal properties of all materials used in the thermal evaluation.

- Technical specification for package components such as valves, pressure relief devices, fabricated insulation, and coatings.

- Environmental conditions used for evaluating design basis events.

- The package contents (isotope mixture) used for the thermal analyses, which might be different from the isotope mixtures used for other analyses because the thermal analyses will use the maximum credible concentrations of those isotopes that are significant heat generators.

- The analytical thermal model of the package, including gaskets, valves, and contents together with any modeling assumptions. 
Safety Assessment Requirements for Onsite Transfers of Radioactive Material (U)

- Any tests performed and the results interpreted in terms of the packaging operating environment.

- Maximum temperatures (and minimum if low temperature is a concern) at locations of concern, including contents, containment vessel, gaskets, and shielding material for design basis events.

- Maximum internal pressure (and minimum if external might be greater than internal) for design basis events.

- The limiting combination of thermal gradient and isothermal stress causing the maximum thermal stress that results from the environments existing during fabrication (including lead pouring), packaging testing, and design basis events.

- Thermal calculation results for the configuration shown by the structural calculations to have the most damage affecting the thermal performance of the package.

- Thermal test results for prototype packages previously subjected to the structural test.

For alternate Type B packages, the design basis events include the normal, anticipated, off-normal, and emergency design basis events.

\subsection{Alternate Type A, IP-2, and IP-3 Packages}

For Type A, IP-2, and IP-3 packagings, the thermal analysis section of the safety assessment document shall either

- describe the thermal engineering design of the packaging and show by comparison with other similar packages, by tests, or by analyses that internal pressures, temperatures, and temperature gradients will have an insignificant effect upon the package performance or

- identify, describe, discuss, and show by analysis or test the principal thermal engineering design of the packaging, components, and systems important to safety and the design performance requirements. The significant thermal design features and operating characteristics of the package should be described. The operation of all subsystems involved in thermal control should be discussed. In addition, this section shall identify or describe the additional items from the list just given in 5.1, Alternate Type B Packages.

For alternate Type A, IP-2, and IP-3 packages, the design basis events include only the normal and anticipated design basis events. 
Safety Assessment Requirements for Onsite Transfers of Radioactive Material (o)

\subsection{Excepted Packages}

A thermal assessment is not required for limited quantity and article packagings (49 CFR 173.423) and IP-1 packagings. 
This page is intentionally blank. 
Safety Assessment Requirements for Onsite Transfers of Radioactive Material (I)

\subsection{CONTAINMENT}

\subsection{Excepted and IP-1 Packages}

Those packages whose contents meet the requirements for

- excepted quantity and article

- instruments and articles

- LSA-I

- SCO-I

- empty

do not require a containment evaluation. See Glossary for explanation of terms in the preceding list.

\subsection{All Other Alternate Packages}

The containment evaluation in the safety assessment document shall identify, describe, and discuss the package containment system. The following elements shall be included in the discussion:

- The containment boundary.

- The containment criteria for each event category established by the package designers.

- Components, closure devices, penetrations, seals, and welds in the containment boundary.

- Summary of design specifications for the components, closure devices, penetrations, seals, and welds in the containment boundary.

- The amount, volatility, dispersibility, and isotopic composition of the package contents used for containment assessment.

- Leak rate after the normal, anticipated, off-normal, and emergency design basis events.

- Summary of results from structural and thermal evaluations pertinent to containment assessment. 
- The effect of internal pressure or explosion of gases or vapors during normal, anticipated, off-normal, or emergency design basis events.

The results of the containment evaluation shall be summarized in a manner that will allow determination of the radiation exposure (i.e., release concentrations) from each of the containment design basis events considered. The consequences of the design basis events for containment shall be summarized. This information shall be provided in the tabular radiation protection summary provided in Chapter 12. 


\subsection{SHIELDING EVALUATION}

\subsection{Excepted and IP-1 Packages}

Those packages whose contents meet requirements for

- excepted quantity and article

- instruments and articles

- LSA-1

- SCO-I

- empty

do not require a shielding evaluation. See Glossary for explanation of items in the preceding list.

\subsection{All Other Alternate Packages}

The shielding evaluation in the safety assessment document should identify, describe, discuss, and analyze the following elements:

- The shielding criteria for each event category established by the package designer.

- Package contents (isotopic composition) used in the model for the shielding analysis.

- Gamma source strength (MeV/sec and photons/sec) as a function of photon energy.

- Models used for the radial and axial shielding analyses, including any voids or irregularities not in the model.

- Material densities $\left(\mathrm{g} / \mathrm{cm}^{3}\right.$ ) and atomic number densities (atoms/barn-cm) for constituent nuclides of all material used in the calculational models.

- Basic method used to determine the gamma and neutron dose rates at selected points outside the package including spatial source distribution, computer program used, attenuation and removal cross-sections, buildup factors, and flux-to-dose-rate conversion factors. 
- Summary of results from the structural and thermal evaluations pertinent to the shielding assessment.

- Calculated radiation rate (mRem/hr) on the side, top, and bottom package surface and at $1 \mathrm{~m}$ from the side, top, and bottom package surface for gamma, neutron, and total radiation.

The results of the shielding evaluation shall be summarized in a manner that will allow determination of the radiation exposure (i.e., external radiation levels from the package) from each of the shielding design basis events considered. The consequences of the design basis events for shielding shall be summarized. This information shall be provided in the tabular radiation protection summary provided in Chapter 12 . 
Safety Assessment Requirements for Onsite Transfers of Radioactive Material (U)

\subsection{CRITICALITY EVALUATION}

Any package meeting the package descriptions in 49 CFR 173.453, "Fissile materials - exceptions" meets the criticality safety for onsite transfers.

Criticality safety for all other onsite packages containing fissile material shall be provided by compliance with applicable:

- DOT regulations

- NRC regulations

- DOE directives.

\subsection{Applicable DOT Regulations}

Alternate onsite packagings that are essentially identical to those DOT specification packagings identified in 49 CFR 173.417 will meet the criticality safety criteria for onsite transfers, provided the assessment shows that they:

- Do not differ from the DOT Specification packaging in any way that might increase the criticality hazard.

- Meet the associated package, vehicle, or package limits included in 49 CFR 173.417.

- Comply with the following regulations:

- 49 CFR 173.451, "Fissile materials - general requirements"

- 49 CFR 173.455, "Classification of fissile materials packages"

- 49 CFR 173.457, "Transportation of Fissile Class III shipment specific requirements"

- 49 CFR 173.459, "Mixing of fissile material packages."

\subsection{All Other Alternate Packages}

NRC regulations, applying to criticality safety of fissile packages, appear in 10 CFR 71. These regulations have been modified slightly to refer to Off-normal and Emergency Events instead of Hypothetical Events. The applicable modified requirements, listed in the Criticality Safety chapter of the criteria document, may be used for any alternate package.

The applicable DOE directive is 5480.5 , "Safety of Nuclear Facilities." This Order provides alternate requirements for establishing and maintaining criticality 
safety during onsite transfers of fissionable material. This order may be used as the criticality safety basis for any alternate package.

If the modified NRC regulations or the DOE directives are used for the basis of criticality safety, the safety assessment document shall:

- Identify, describe, discuss, and analyze the principal criticality engineeringphysics design of the packaging components or systems important to criticality safety.

- Describe the significant criticality safety design features of the packages.

- Discuss the operation of all subsystems involved in criticality safety.

- Discuss the possibility of water flooding.

- Discuss the loss or failure of components such as baskets, canisters, cushioning, or spacers for inner containers that could allow contents to become rearranged.

This section shall identify or describe the following additional items:

- Package contents used in the model for the criticality safety analyses.

- Geometric model used in the analyses and differences between the model and the actual package configuration.

- Material densities $\left(\mathrm{g} / \mathrm{cm}^{3}\right)$ and the atomic number densities (atoms/barn-cm) for constituent nuclides of all materials used in the calculational models.

- Basic calculational method used to calculate the effective multiplication constant of the package, the computer program, neutron cross-sections, approximations, boundary conditions, calculational convergence criteria, cross-section adjustments, and calculational bias from comparison with benchmarks.

- Results of reactivity calculations establishing the most reactive configurations for the single package and arrays of packages for the appropriate design basis events.

The criticality evaluation is conducted in accordance with the requirements in the criteria document, Chapter 6.

A conclusion regarding the criticality safety of the package and compliance with the requirements for criticality safety in the criteria document shall be presented in this section of the safety assessment. 


\subsection{OPERATING PROCEDURES}

\subsection{Excepted and IP-1 Packages}

This section of the safety assessment document for packages containing limited quantities of radioactive material and packages for instruments and articles (49 CFR 173.423) and IP-1 packages shall identify operating procedures to be used to ensure that the package contents would qualify for offsite shipment in an excepted or IP-1 package.

\subsection{All Other Alternate Packages}

\subsubsection{Operating Procedure Description}

For all other packages, this section of the safety assessment document shall provide a summary description of the generic procedures to be used in the transfer-related operational activities (see Glossary) and the transfer activities (see Glossary). This summary description shall include the following, if applicable:

- Inspections, tests, and special preparations of the package for loading.

- Inspections or testing of the package prior to or during loading to ensure that the package is not damaged.

- Inspections to ensure that the exterior surface contamination levels (and interior on empty packages) are acceptable.

- Inspection of gaskets and other closure devices, criteria for replacement, and repair procedures.

- Limits on use of lifting lugs or slings.

- Need for use of internal bracing, shoring, or spacer devices.

- Installation of package closure including the use of alignment guides or marks, thread lubricant or sealant, and torque requirements.

- Procedures for removal of residual moisture from cavities intended to be dry.

- Inspections, tests, and special preparations of the package for unloading.

- Safe removal during unloading of fission gas or gas from other sources of internal pressure, contaminated coolant, or solid contaminants. 
- Inspections, tests, and special preparations for shipping of the packaging when empty.

This section of the safety assessment document shall also list any QA package requirements and any other limitations or requirements that must be fulfilled by specific operating procedures. The procedures used to ensure that these limitations or requirements are implemented should be described.

The summary description of these procedures should be presented sequentially in the expected order of performance.

\subsubsection{Operating Procedure Assessment}

The procedure descriptions should show that the procedures will result in radiation exposures that are ALARA (both collective exposure and exposure to the maximum exposed individual).

The procedure descriptions should also show that the procedures will ensure that the safety components and safety systems will perform as intended. 


\subsection{ACCEPTANCE TESTING AND MAINTENANCE PROGRAM}

This section of the safety assessment document shall identify the tests, inspections, and maintenance activities required to ensure that the safety components and systems will perform as intended. Consideration shall be given to the following list in developing the list of required tests, inspections, and maintenance activities.

- Visual inspections to be performed before first use, the specific purpose for each inspection, acceptance criteria, and action if noncompliance is encountered.

- Tests on the containment vessel before first use, acceptance criteria, test sensitivity estimate, and inspections of or tests on valves, rupture discs, fluid transport devices, gaskets, or other important components.

- Inspections of or tests on valves, rupture discs, fluid transport devices, gaskets, or other important components before first use.

- Inspections of or tests on duplicate valves, rupture discs, fluid transport devices, gaskets, or other important components to avoid damage from testing to actual component together with a quality assurance program ensuring that the test results represent performance of actual component.

- Shielding tests before first use including dimensions and geometrical scope of grid pattern, scanning procedure, acceptance criteria, and action to be taken if noncompliance is encountered in shield integrity.

- Thermal tests before first use including heat source, instrumentation, thermocouple locations, environmental variations, test procedure, estimate of test sensitivity, acceptance criteria, and action to be taken if noncompliance is encountered.

- Visual inspections and maintenance activities for the containment boundary, frequency of inspection, specific purpose for each inspection, acceptance criteria, and action if noncompliance is encountered.

- Tests and maintenance activities for the containment vessel, frequency of tests, acceptance criteria, test sensitivity estimate, and action if noncompliance is encountered.

- Inspections, tests, and maintenance activities for valves, rupture discs, fluid transport devices, gaskets, lifting and tie-down components, or other important components, frequency of inspections or tests, acceptance criteria, and action if noncompliance is encountered. 
This page is intentionally blank. 


\subsection{PACKAGE QUALITY ASSURANCE}

\subsection{Alternate Type B Packages}

For Type B packages, this section of the safety assessment document shall identify the activities required to ensure that the package components and systems important to safety will perform as intended.

This section of the safety assessment document shall include a tabulation of the following elements:

- components and systems important to safety

- safety function of each component or system

- failure mode for each component or system that could jeopardize safety.

This section of the safety assessment document shall include:

- a description of the quality assurance program developed for the package

- a discussion of how the quality assurance program meets the criteria established for quality assurance in the quality assurance chapter of the criteria document.

\subsection{All Other Alternate Packages}

For all alternate packages containing less than an $A_{1}$ or $A_{2}$ quantity of radioactive material per package or containing LSA material, this section of the safety assessment document shall identify the activities required to ensure that the package performs as intended.

This section of the safety assessment document shall include:

- a description of the quality assurance program developed for the package, and

- a discussion of how the quality assurance program meets the criteria established for quality assurance in the quality assurance chapter of the criteria document. 
This page is intentionally blank. 


\subsection{RADIATION PROTECTION ASSESSMENT}

\subsection{Excepted and IP-1 Packages}

Those packages whose contents meet the requirement for:

- expected quantity and article

- instruments and articles

- LSA-1

- SCO-I

- empty

do not require a radiation protection assessment. (See Glossary for explanation of terms in the preceding list.)

\subsection{All Other Alternate Packages}

A description of the radiation protection assessment is provided in this chapter of the safety assessment document for all alternate packages that do not meet the requirements of Section 12.1 .

This radiation protection assessment shall include the following:

- description of method used for making exposure predictions

- description of all assumptions used in making exposure predictions

- reference to and summarization of operating procedures used for transfer activities or description of assumed generic operating procedures

- listing of isotopic contents used for shielding assessment

- listing of isotopic contents used for containment assessment

- description of the basis for any reduction in release amounts because of confinement boundaries or barriers

- conclusion regarding effectiveness of packaging in meeting ALARA and radiation protection criteria listed in Chapter 10 of the criteria document. 
The exposures from airborne (containment), ingested (contamination), and radiation (shielding) shall be summarized in a tabulation containing the information provided in the example radiation protection summary form. 


\section{RADIATION PROTECTION SUMMARY}

\section{EXAMPLE SUMMARY}

A. Annual Personnel Exposure (Maximum Exposed Individual)

[********************EXPOSURE,mrem/yr*****************]

NORMAL EVENTS AIRBORNE INGESTED EXTERNAL TOTAL ALLOWABLE

Load vehicle

Transport

Unload Vehicle

B. Exposure per Event
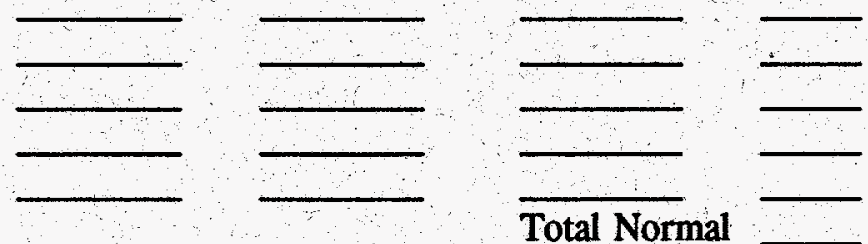

Total Normal

What are the Design Basis Anticipated Events (DBAE)

What are the containment, shielding, and package contamination consequences of these events

What are the Design Basis Off-Normal Events (DBOE)

What are the containment, shielding, and package contamination consequences of these events

What are the Design Basis Emergency Events (DBEE)

What are the containment, shielding, and package contamination consequences of these events

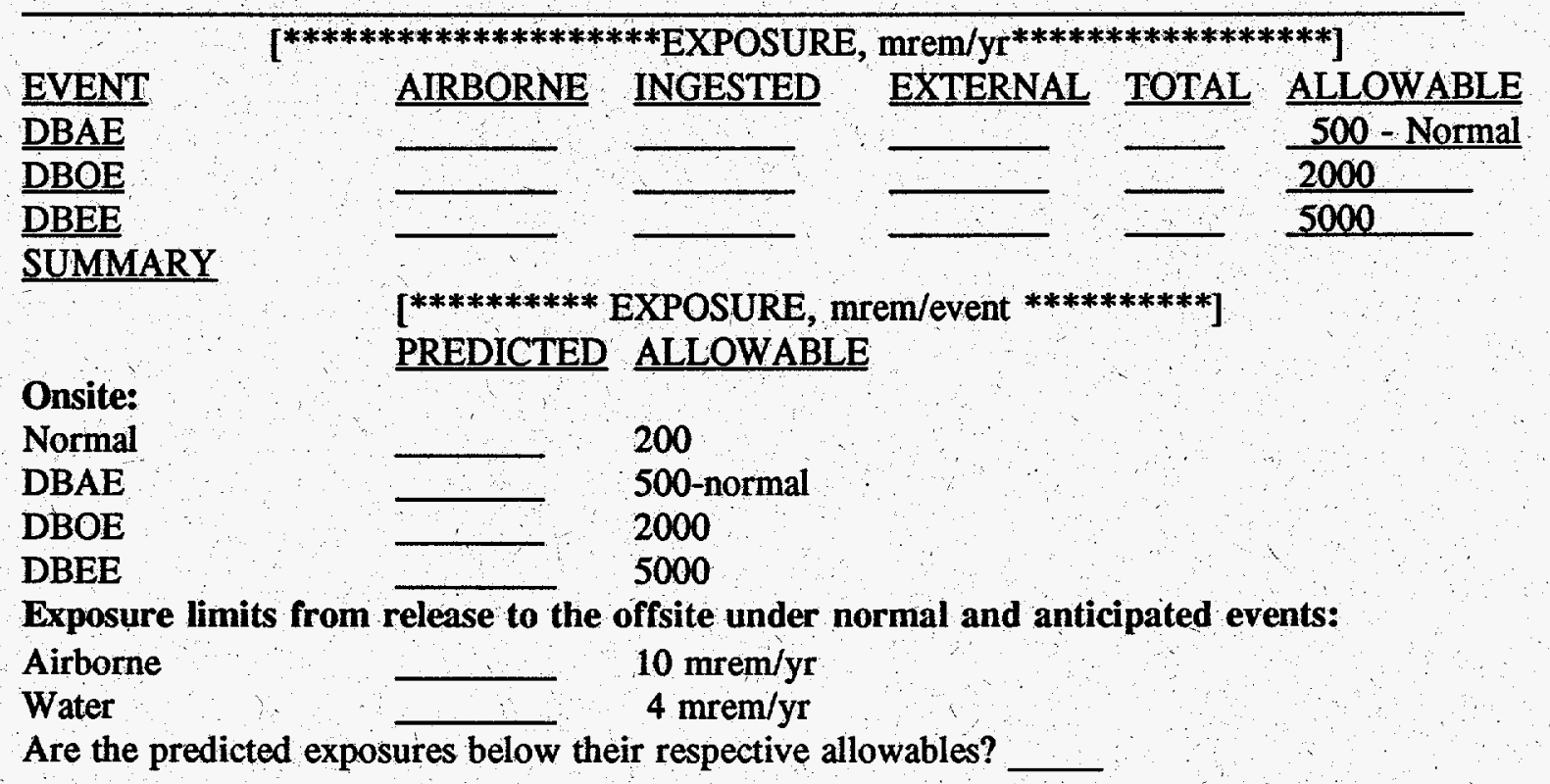


This page is intentionally blank. 


\subsection{HAZARDS INFORMATION ASSESSMENT}

An assessment of the procedure for providing hazards information to transfer workers and emergency responders shall be described and evaluated in this chapter of the safety assessment document for all onsite packages.

If locally approved procedures are to be used, their approval status shall be stated. The information provided by the procedure used shall be compared with the requirements of provided in the hazards information criteria chapter of the criteria document. $A$ conclusion shall be stated regarding this comparison. 
Safety Assessment Requirements for Onsite Transfers of Radioactive Material (i)

This page is intentionally blank. 


\subsection{ASSESSMENT RESULTS AND REQUIREMENTS}

This chapter shall be included in all safety assessment documents.

In the results section, estimated radiation exposure shall be compared with the allowed limits, the degree of subcriticality margin shall be identified, and the procedure for providing hazard information shall be summarized.

The requirements section shall compile all assumptions used in the assessments and identify specific requirements and constraints necessary to provide the quoted radiation exposure, criticality safety, and emergency response information. The requirements section of this chapter defines the authorized operating conditions for this package.

\subsection{Results}

In the results section of this chapter the safety assessments shall be summarized in such a manner that the conclusion that the criteria were met is readily reached.

Safety during radioactive material transfers depends upon providing the following:

- protection from radiation exposure for workers, members of the public, and the environment

- criticality safety

- hazards information.

Therefore, these subject areas should be the framework upon which the results section of this chapter is developed.

The radiation exposure calculations shall be summarized in this section and these results shall be compared with allowable values. A conclusion should be stated regarding compliance with radiation exposure criteria.

Any package or equipment design features used for providing criticality safety should be identified. The results of criticality calculations should be summarized. A conclusion should be stated regarding compliance with criticality safety criteria.

The procedures for providing hazards information shall be summarized in this section. If locally approved procedures are used, these should be described sufficiently to permit a conclusion concerning whether the information provided is equivalent to that provided by the DOT regulations on placards, package marking and labeling, shipping papers, and emergency response information. A conclusion should be stated regarding compliance with the hazards information criteria. 
Safety Assessment Requirements for Onsite Transfers of Radioactive Material (I)

For alternate packages used to transfer radioactive waste material, discuss how the EPA requirements for package marking and labeling and shipping papers are met.

\subsection{Requirements}

The requirements section of this chapter in the safety assessment document shall serve as the source for the requirements, limitations, authorized contents, and authorized package usage on the "Onsite Package Authorization" form. To accomplish this, assumptions must be identified. For example, assumptions may have been made that the ambient air temperature would not exceed $100^{\circ} \mathrm{F}$ during transport, or that the transport vehicle would be load tested immediately prior to the onsite transfer. Assumptions of this nature should be compiled in this chapter of the safety assessment document.

- The following package evaluation areas should be reviewed to identify these assumptions:

- the list of design basis events

- structural performance

- thermal performance

- radiation exposure

- criticality safety

- operating procedures

- packaging quality assurance

- providing hazards information.

All assumptions important to safety need to be converted into operational requirements and listed in this chapter for inclusion on the "Onsite Package Authorization" form.

In the requirements section of this chapter in the safety assessment document, the following summaries shall also be provided:

- The summary of the package contents characteristics in Chapter 2, Section 2.2 of the safety assessment document shall be recorded.

- The summary of the package usage information in Chapter 2, Section 2.3 of the safety assessment document shall be recorded. 
Safety Assessment Requirements for Onsite Transfers of Radioactive Material (U)

\section{GLOSSARY}

For purposes of onsite transfer of radioactive materials, the following definitions are established.

ALARA is a process to ensure that personnel radiation exposures is as low as reasonably achievable.

An ALARA study includes an assessment of the expected radiation exposure during both transfer activities and transfer-related operational activities.

An alternate package is any package that is not an authorized offsite package. Alternate packages are authorized for use by approval of a written safety assessment. An alternate package shall be used in accordance with all controls and limits identified in its safety assessment.

An authorized offsite package is packaging authorized by and in total compliance with DOE Order 5480.3.

A credible event is any event that has a reasonable probability of occurring. The credible event categories considered in a safety assessment for an onsite package are defined here.

$\begin{array}{ll}\text { Event Type } & \text { Probability Range } \\ \text { Normal } & 1 / \text { transfer } \\ \text { Anticipated } & 10^{-1} / \mathrm{yr} \leq \text { probability }<1 / \text { transfer } \\ \text { Off-normal } & 10^{-4} / \mathrm{yr} \leq \text { probability }<10^{-1} / \mathrm{yr} \\ \text { Emergency } & 10^{-6} / \mathrm{yr} \leq \text { probability }<10^{-4} / \mathrm{yr}\end{array}$

Events with a probability of less than $10^{-6} / \mathrm{yr}$ are defined as incredible and are not considered in the safety assessment for onsite transfers of radioactive material.

Criticality safety is the system of conservative assumptions, calculations, moderators, neutron absorbers, spacers, package material limits package labels, and other controls that ensures maintaining a subcritical fissionable mass during use, handling, and transfer of fissile material.

The design basis is set of environmental and loading conditions that the packaging might reasonably experience during its intended use. If the package will be used for storage, the storage conditions are part of the design basis. The design basis includes the following.

- Amount and isotopic composition ranges of package contents

- Operational restraints or special requirements including maximum and minimum temperatures, maximum pressures, and maximum structural loads experienced during normal, anticipated, off-normal, and emergency events, and during any use of the package for material storage 
- Design criteria for structural, thermal, containment, criticality, and shielding analysis and the fabrication acceptance.

Note: The design requirements for use of the package in storage are included in the overall design basis but are not considered in the safety assessment of the package for onsite transfer.

Design basis events are the credible scenarios upon which the package analysis is based. Each design basis event shall be the combination of the worst-case credible event for that event category and the worse-case combination of radionuclides for the failure mode of interest.

An empty package is one that has previously contained radioactive material and has been emptied of contents, insofar as practical, and has surface radiation below $0.5 \mathrm{mRem} / \mathrm{hr}$, meets the exterior surface contamination limits established by DOT, and contains less than $15 \mathrm{~g}$ of residual uranium.

Equivalent protection is a level of protection provided during onsite transfers of radioactive material including radiation protection, criticality safety, and hazards information equivalent to that of offsite shipments. In order to be equivalent the radiation protection must be in compliance with the recommendations of the National Council on Radiation Protection and Measurements (the limits and requirements in offsite regulations are derived to provide this level of radiation protection). In addition the criticality safety. and hazards information provided must be equivalent to that provided for offsite shipments.

Excepted quantities and articles are small quantities of radioactive materials that meet the limits in 49 CFR 173.423 .

Hazards information is the information provided to workers, emergency responders, and other persons about the hazards of material being transported. The information is provided by means of placards, package markings, package labels, shipping papers, and the emergency response information or by other alternate means.

An intrafacility movement is movement of hazardous material within a facility. (Criteria for these movements is not within the scope of this document.)

Instruments and articles are instruments and manufactured articles containing small amounts of radioactive material. Each instrument or article shall contain no more than $10^{-2} \mathrm{~A}_{2}$ of solid radioactive material or no more than $10^{-3} \mathrm{~A}_{2}$ of gaseous radioactive material.

Limited quantity is radioactive material that does not exceed the following amount per package:

- $10^{-3} \mathrm{~A}_{1}$ for special-form material 
Safety Assessment Requirements for Onsite Transfers of Radioactive Material (U)

- $10^{-3} \mathrm{~A}_{2}$ for non-special-form material

- $1000 \mathrm{Ci}$ of tritiated water if the specific activity is less than $0.2 \mathrm{Ci} / \mathrm{L}$

- $100 \mathrm{Ci}$ of tritiated water if the specific activity is from $0.1 \mathrm{Ci} / \mathrm{L}$ to $1 \mathrm{Ci} / \mathrm{L}$

- $1 \mathrm{Ci}$ of tritiated water if the specific activity is equal to or greater than $1 \mathrm{Ci} / \mathrm{L}$

- $10^{-4} \mathrm{~A}_{2}$ for liquids other than tritiated water

- $\quad 20$ Ci of tritium gas

- $10^{-3} \mathrm{~A}_{2}$ for gas in special form

- $10^{3} \mathrm{~A}_{2}$ for gas in non-special form.

LSA is radioactive material that by its nature has a limited specific activity. External shielding materials surrounding the LSA material shall not be considered in determining the estimated average specific activity. LSA material shall be in one of three groups:

- LSA-1 is any one of the following materials:

- Ores containing naturally occurring radionuclides (e.g., uranium, thorium), and uranium or thorium concentrates of such ores.

- Solid unirradiated natural uranium or depleted uranium or natural thorium or their solid or liquid compounds or mixtures.

- Radioactive material, other than fissile material, for which the $A_{2}$ value is unlimited.

- LSA-II is any one of the following materials:

Water with tritium concentration no greater than $20 \mathrm{Ci} / \mathrm{L}$.

- Other material in which the activity is distributed throughout and the estimated average specific activity does not exceed $10^{-4} \mathrm{~A}_{2} / \mathrm{g}$ for solids and gases and $10^{-5} \mathrm{~A}_{2} / \mathrm{g}$ for liquids.

- LSA-III is a solid (e.g., consolidated wastes, activated materials) for which each of the following is true:

- The radioactive material is distributed throughout a solid or a collection of solid objects, or is essentially uniformly distributed in a solid compact binding agent (such as concrete, bitumen, ceramic, etc.). 
Safety Assessment Requirements for Onsite Transfers of Radioactive Material (U)

- The radioactive material is relatively insoluble, or it is intrinsically contained in a relatively soluble matrix, so that, even under loss of packaging, the loss of radioactive material per package by leaching when placed in water for 7 days would not exceed $0.1 \mathrm{~A}_{2}$.

- The estimated average specific activity of the solid, excluding any shielding material does not exceed $2 \times 10^{-3} \mathrm{~A}_{2} / \mathrm{g}$.

A manufactured article is an article in which the sole radioactive material content is natural or depleted uranium or natural thorium and the outer surface of the uranium or thorium is enclosed in an active sheath made of metal or other durable protective material.

Members of the public are persons who have no occupationally related reason for being onsite or who have not received appropriate radiation protection and training.

Normal events include all events that are expected to occur.

An offsite shipment of radioactive material is transported on a motorized vehicle to or from a location outside the boundary of SRS but accessible to the public. The portion of an offsite shipment that might occur on roads within the boundary of SRS but not accessible to the public is part of the offsite shipment provided the offsite carrier continues the transport as part of the offsite shipment.

An onsite transfer of radioactive material is transport of radioactive material on a motorized vehicle over routes from which members of the public have been excluded. Intrafacility movements are not considered onsite transfers. See separate definition.

An over-pack is the container used to provide protection during transport, to add convenience in handling a package or to consolidate two or more packages.

Radiation exposure is exposure to ionizing radiation from internal or external sources. External radiation exposure comes from radiation emanating from the package, primarily gammas and neutrons, and from material released from the package. Internal radiation exposure may occur from inhalation or ingestion of radiation material released from the package. Leaking packages contribute to airborne radioactive material as a source for inhalation. Surface contamination of any package with nonfixed radioactive material is a source for an external dose to the skin or an internal dose from ingestion of the material.' Immersion in an airborne cloud of some radioactive material may cause external radiation exposure or lead to internal radiation exposure by absorption through the skin in addition to inhalation.

Radiation exposure to transfer workers is exposure during transfer activities. (See definition for transfer activities and for transfer-related operational activities.)

A radiation protection program is the system of requirements, controls, measurements, and limits that accomplishes the following: 
Safety Assessment Requirements for Onsite Transfers of Radioactive Material (U)

- Ensures that activities are conducted only if the benefit is greater than the health effects from the radiation exposure

- Manages activities associated with radioactive materials to ensure the exposure is ALARA

- Predicts anticipated exposure and ensures that it is below established limits

- Measures and records personnel radiation exposure to confirm predictions

- Conducts medical exams, tests, and bioassays to confirm dosimeter and other measurements.

Radioactive material is material meeting the definition in 49 CFR 173.403 or material otherwise defined as radioactive by a cognizant federal agency.

A safety assessment is a written assessment of the activities, hardware, and equipment involved in an onsite transfer to determine if the radiation protection, criticality safety, and hazards information provided meets the criteria established in the criteria document. The criteria were derived to ensure that the protection provided is equivalent to that provided during offsite shipments. Assessment of radiation protection requires containment and shielding assessments. These assessments in turn require thermal and structural assessments of normal and accident conditions. The safety assessment identifies the authorized contents of the onsite package.

A safety assessment document establishes, collects, and enumerates requirements for procedures such as loading and closing the packaging, inspections and tests, lifting and hoisting activities, and tie-downs. The safety assessment document also establishes and enumerates limits such as contents weight or activity per package, isotopic concentrations, decay heat, transfer vehicle speed, and number of packages per vehicle.

SCO is a Surface Contaminated Object, which is a solid object that is not itself radioactive but that has radioactive material distributed on its surfaces.

SCO shall be in one of two groups:

- SCO-I is a solid object on the surface of which contamination is characterized as follows:

- The nonfixed contamination on the accessible surface averaged over $300 \mathrm{~cm}^{2}$ (or the area of the surface if less than $300 \mathrm{~cm}^{2}$ ) does not exceed $10^{-4} \mu \mathrm{Ci} / \mathrm{cm}^{2}$ for beta and gamma emitters, or $10^{-5} \mu \mathrm{Ci} / \mathrm{cm}^{2}$ for alpha emitters.

- The fixed contamination on the accessible surface averaged over $300 \mathrm{~cm}^{2}$ centimeters (or the area of the surface is less than $300 \mathrm{~cm}^{2}$ ) does not exceed $1 \mu \mathrm{Ci} / \mathrm{cm}^{2}$ for beta and gamma emitters, or $0.1 \mu \mathrm{Ci} / \mathrm{cm}^{2}$ for alpha emitters. 
Safety Assessment Requirements for Onsite Transfers of Radioactive Material (v)

- The nonfixed contamination plus the fixed contamination on the accessible surface averaged over $300 \mathrm{~cm}^{2}$ (or the area of the surface if less than $300 \mathrm{~cm}^{2}$ ) does not exceed $1 \mu \mathrm{Ci} / \mathrm{cm}^{2}$ for beta and gamma emitters, or $0.1 \mu \mathrm{Ci} / \mathrm{cm}^{2}$ for alpha emitters.

- SCO-II is a solid object on the surface of which either the fixed or nonfixed contamination exceeds the applicable limits specified for SCO-I and on the surface of which contamination is characterized as follows:

- The nonfixed contamination on the accessible surface averaged over $300 \mathrm{~cm}^{2}$ (or the area of the surface is less than $300 \mathrm{~cm}^{2}$ ) does not exceed $10^{-2}$ $\mu \mathrm{Ci} / \mathrm{cm}^{2}$ for beta and gamma emitters or $10^{-3} \mu \mathrm{Ci} / \mathrm{cm}^{2}$ for alpha emitters.

- The fixed contamination on the accessible surface averaged over $300 \mathrm{~cm}^{2}$ (or the area of the surface is less than $300 \mathrm{~cm}^{2}$ ) does not exceed $20 \mu \mathrm{Ci} / \mathrm{cm}^{2}$ for beta and gamma emitters, or $2 \mu \mathrm{Ci} / \mathrm{cm}^{2}$ for alpha emitters.

- The nonfixed contamination plus the fixed contamination on the accessible surface averaged over $300 \mathrm{~cm}^{2}$ (or the area of the surface if less than $300 \mathrm{~cm}^{2}$ ) does not exceed $20 \mu \mathrm{Ci} / \mathrm{cm}^{2}$ for beta and gamma emitters, or $2 \mu \mathrm{Ci} / \mathrm{cm}^{2}$ for alpha emitters.

Special form is radioactive material which has the following characteristics.

- The material is a single solid piece or is contained in a sealed capsule that can be opened only by destroying the capsule.

- The piece or capsule has at least one dimension not less than $0.5 \mathrm{~cm}$, and passes through the tests prescribed by DOT for special-form material (49 CFR 173.469).

Subsidiary hazards of the radioactive material are characteristics such as flammability, toxicity, chemical instability, corrosivity, explosivity, or other hazardous characteristics that may exist or develop during transport.

Transfer activities are as follows:

- loading packages onto transfer vehicle

- blocking, bracing, and tie-down activities to secure packages to transfer vehicle

- operating transfer vehicle

- unloading transfer vehicle.

The radiation exposure expected during these activities is considered in determining whether the package meets its radiation exposure goals and limits. 
The following activities are defined as transfer-related operational activities for the purposes of the safety assessment:

- preparing material for transfer

- packaging preparation

- putting material into the packaging

- closing the package

- any package inspection or testing

- temporary storage of filled package awaiting transfer

- long-term storage of filled package

- opening the package

- emptying the package.

The transfer-related operational activities are not included in the determination of radiation exposure chargeable to onsite transfers of radioactive material. The transfer-related operational activities are considered part of the facility operations. Therefore, these transfer-related operational activities and any credible events associated with them are not evaluated in the safety assessment for onsite transfers. However, these transfer-related operational activities are included in the package selection process when performing an ALARA study to assure that the packaging selected for a particular material and process stream does indeed reduce the radiation exposure to ALARA levels.

A Type A package is one authorized to carry greater than an $A_{1}$ quantity of special-form radioactive material or an $A_{2}$ quantity of non-special-form radioactive material.

A Type B package is one authorized to carry greater than an $A_{1}$ quantity of special-formradioactive material or greater than an $A_{2}$ quantity of non-special-form radioactive material. 
This page is intentionally blank. 